\title{
The Simple Analytics of Informed Finance*
}

\author{
Dan Bernhardt and Stefan Krasa \\ Department of Economics \\ University of Illinois \\ Champaign IL 61820 \\ http://www.staff.uiuc.edu/ skrasa \\ danber@uiuc.edu
}

September, 2005

\begin{abstract}
The paper derives two analytical consequences of informed finance: Equity leads to under-financing, while debt leads to over-financing. We show that our model can explain key qualitative and quantitative features of informed venture capital finance in the United States. Using only four model parameters we match: (1) the venture capitalist's equity share; (2) the venture capitalist's expected return and (3) its standard deviation; (4) the probability that a project receives funding; and (5) the probability the venture capitalist loses money on an investment. Our estimated parameters reveal the average quality of an unfunded project; the percentage of uncertainty resolved by the venture capitalists investigation; the percentage of total surplus accruing to the venture capitalist, and the magnitude of underfinancing associated with venture capital finance.
\end{abstract}

\footnotetext{
*Dan Bernhardt gratefully acknowledges financial support from NSF grant SES-0317700. Stefan Krasa gratefully acknowledges financial support from NSF grant SES-0318394 and NCSA computation grant SES050001. We are grateful to Per Stromberg for helping us uncover the relevant empirical regularities. We thank John Cochrane for giving us access to his data and appreciate the guidance that he provided us. We also thank Burton Hollifield, George Pennacchi, Jano Zabojnik and seminar participants at the University of Illinois, Babson College, Virginia Tech, University of Toronto, University of Montreal, and the Federal Reserve Bank of Cleveland.
} 


\section{Introduction}

Our paper derives the simple analytical consequences of two well-established facts about venture capital finance. First, venture capitalists are better judges than entrepreneurs of a project's economic viability (see Garmaise [13], and references therein). ${ }^{1}$ Second, startup projects require significant entrepreneurial capital from founders and key personnel. This entrepreneurial capital includes the "market value" of patents and product ideas, personal capital, under-compensated and extensive time inputs (sweat equity), reputation, connections and expertise.

We derive the qualitative and quantitative implications of these two facts. We first suppose that the financier is a venture capitalist who provides capital in exchange for an equity share of the project. We show that venture-capital finance leads to under-financing. That is, a venture capitalist who is compensated with equity fails to fund some projects that he expects to have a positive NPV. Here, a project has a positive NPV if, post-investigation, project payoffs are expected to cover the opportunity cost of the capital investment plus the entrepreneurial capital.

This raises the question: If equity leads to under-financing, why not use debt instead? We show that debt may be unattractive for the opposite reason: debt can lead to over-financing. That is, an informed lender may have the incentive to fund some projects whose payoffs he expects will cover his opportunity cost of capital, but will not fully compensate the entrepreneur and key personnel for their inputs. Further, if the projects are too risky, debt finance may result in infeasibly high interest and default rates.

We then show that these simple analytics explain the key qualitative and quantitative features of venture capital finance in the United States. We also offer insights into why the projects that receive venture capital finance would not be candidates for debt finance.

In our model, an entrepreneur has a project that requires external capital. The entrepreneur understands that an informed financier serves two key roles. First, the financier provides the required capital. Second, the financier investigates and filters entrepreneurial projects. ${ }^{2}$ Following an investigation, a financier will fund projects that seem promising and discard those whose prospects seem poor. Entrepreneurs recognize that while they may have potentially valuable inventions, they may not be good judges of implementability or market value. This reflects that in practice, most entrepreneurs are associated with only a few projects. In contrast, venture capitalists have extensive industry experience. Their extreme specialized knowledge permits venture capitalists to distinguish winners from losers (Fenn, Liang and Prowse [11]): venture capitalists

\footnotetext{
${ }^{1}$ Venture capitalists also identify appropriate marketing strategies and key personnel (Byers [6], Bygrave and Timmons [7], Gorman and Sahlman [14], Helmann and Puri [16], and Sapienza [23]).

${ }^{2}$ Kaplan and Stromberg [17] document empirically the significant time and effort spent by venture capitalists to evaluate and screen investment opportunities.
} 
scrutinize serious projects intensively (Fried and Hisrich [12], Garmaise [13], Kaplan and Stromberg [17]), and reject about 90 percent of those that they investigate seriously.

Consider what happens if equity finance is pursued. At a minimum, for a venture capitalist to provide funding, his share of the project's expected payoff conditional on his investigation must cover his opportunity cost of capital. The entrepreneur understands this when negotiating the prospective equity terms. As a result, to increase his chances of funding, the entrepreneur willingly cedes an equity share that generates a significant excess return for the venture capitalist. That is, the equity share more than covers the opportunity cost of the venture capitalist's investments plus his investigation costs.

To understand the source of under-financing, recognize that a venture capitalist expects the payoffs from the marginal funded project to just cover his opportunity cost of capital. Ignoring investigation costs, a venture capitalist therefore expects to make money on all better projects. If investigation costs are not too high and the proposed equity terms do not give the venture capitalist an excess return, then it necessarily follows that the marginal project funded must be close to the median project funded. The marginal project must therefore be very good, implying that many positive NPV projects go unfunded. Recognizing this, entrepreneurs negotiate equity terms that trade off between raising the probability of getting funded against ceding too much on very good projects.

To investigate the quantitative implications, we then estimate our model parameters. The data pin down five endogenous variables of the model: the venture capitalist's equity share (43\%); the venture capitalist's expected excess return $(28 \%)$ and its standard deviation $(120 \%)$; the probability that a project receives funding (10\%); and the probability the venture capitalist loses money on an investment (41\%). There are four exogenous variables for which reliable data are not available: the share of inputs that is entrepreneurial capital, the mean and variance of the ex-ante project payoff and the fraction of uncertainty resolved through a venture capitalist's investigation. We estimate these four parameters by minimizing the difference between the predicted and empirical values of the exogenous parameters. Our four estimated exogenous parameters do an astonishingly good job of matching the five endogenous variables: All of the predicted values differ by less than one percent from their empirical counterparts. To emphasize the nature of the fit:

- Note that it is typically impossible to match five moments closely with only four parameters.

- We show that the model and its predictions are robust. We are careful to account for the fact that the empirical moments that we seek to match, are themselves noisy estimates. We calculate $95 \%$ confidence intervals for each primitive parameter, and show that these intervals are tight compared to the error that we allow for in the empirical moments.

- Conversely, we show that the model would fit far less well if the empirical values were very different. 
- We document that our estimates of the primitive parameters of venture capital finance make significant economic sense.

Perhaps even more important than the direct fact that our theoretical model robustly explains the empirical characteristics of venture capital finance so well, is the implication that we can use our model to back out predictions for features of venture capital projects that would otherwise be impossible to obtain. For example, we quantify the under-financing associated with venture capital: our primitive parameter estimates imply that only $40 \%$ of all projects with positive expected NPVs following a venture capitalist's are funded. We find that while $57 \%$ of all projects have negative NPVs, the venture capitalist's filtering reduces this number to $36 \%$ for funded projects. By eliminating likely losers, a venture capitalist's investigation dramatically raises the expected project return from $-17 \%$ to $64 \%$, even though the standard deviation of the project's payoff is almost unaffected. One can also use our estimates to measure the percentage of ex-ante project surplus (i.e., accounting for the costs of investigating both funded and unfunded projects) that accrues to the venture capitalist. For reasonable investigation costs, the venture capitalist's share of the surplus is about $20 \%$, which, because it is pure rent, is quite a large number.

Finally, our model can reconcile why projects receiving venture capital finance are not good candidates for debt finance. If debt were used instead of equity, the investor would not receive the upside gains when the project is very successful, but the investor would incur downside losses when the project fails. We find that just to break even, a lender would have to charge unreasonably high interest rates that exceed 80 percent, and face default probabilities that exceed 35 percent. Even ignoring all bankruptcy costs, given institutional constraints on standard lenders, debt finance is infeasible for such risky projects.

\subsection{Related Literature}

There is an enormous literature that documents the apparently excessive returns that venture capitalists make (see, e.g., Cochrane [9] or Ljungqvist and Richardson [19]). The accepted wisdom is that these returns are hard to reconcile theoretically in a setting where venture capitalists do not have monopoly power. Ljungqvist and Richardson [19] suggest that this excess return is a premium for the illiquidity of the investment. Here, we show that even though an entrepreneur could negotiate competitive equity terms that just cover the venture capitalist's opportunity cost of capital plus investigation costs, it is optimal for the entrepreneur to give the venture capitalist such a large equity share that we match the empirically-observed excess return.

Other models of entrepreneurial finance in which a venture capitalist can become better informed than the entrepreneur include Biais and Perotti [5], Ambec and Poitevin [2], Ueda [24], Bernhardt and Krasa [4] and Garmaise [13]). In the first three papers, the venture capitalists can better assess and implement a project, but the entrepreneur has to worry about stealing/free-riding on his idea/information. In contrast, 
in Bernhardt and Krasa, it is the informed financier (the expert) who is concerned about free-riding by uninformed potential investors.

There is also a large theoretical literature that introduces incomplete contracts and moral hazard of various forms to explain the choice of control right assignments and the division of cash flows. Representative papers include Aghion and Bolton [1], Dewatripont and Tirole [10], Hart and Moore [15], Repullo and Suarez [22], Bergemann and Hege [3], and Winton and Yerramilli [25]. Our paper shares the feature that the interests of the entrepreneur may not be aligned with the financier's, but in contrast to this literature, we do not introduce moral hazard, and control rights play no role. A problem with introducing moral hazard to a quantitative model is that it can neither be measured nor estimated readily. Furthermore, introducing additional parameters generates identification problems for determining the primitive parameters of venture capital finance. The purpose of this paper is to derive the qualitative and quantitative effects of informed debt and equity finance, the contracts that closely mirror those used in practice. Accordingly, we develop a sparsely-specified model with minimal free parameters and focus on pure debt and equity contracts, rather than specifying all primitive frictions and characterizing the fine details of the optimal contract. ${ }^{3}$ The fact that our empirical analysis indicates that linear equity contracts explain the data well suggests that the nonlinearities in real world contracts are only of secondary importance.

\section{The Model}

Consider a potential entrepreneur with a project. The project requires $w$ units of entrepreneurial capital and $1-w$ units of external finance to generate output $X+Y$, where $X$ and $Y$ are independent random variables. Without loss of generality, we normalize $Y$ to have mean zero. We denote realizations of $X$ and $Y$ by $x$ and $y$, respectively. We assume that $X$ is distributed according to the density $f(x)$ and $Y$ is distributed according to the density $g(y)$. The associated cdfs are $F(x)$ and $G(y)$. We assume that both $f(x)$ and $g(y)$ are strictly positive on their (possibly unbounded) supports. At a cost of $c>0$, a financier can investigate the project and learn the realization $x$ of $X$, thereby reducing the uncertainty about the project's payoff to $x+Y$. We assume that there are realizations $x_{1}$ and $x_{2}$ with $f\left(x_{1}\right), f\left(x_{2}\right)>0$ such that $x_{1}>1+r_{i}>x_{2}$, where $r_{i}$ is the risk-adjusted required expected rate of return for the venture capitalist's funds. This condition ensures that post-investigation some, but not all, projects have positive NPVs. This is a necessary condition for investigation to have value. The opportunity cost to the financier of investing $(1-w)$ in the project is $\left(1+r_{i}\right)(1-w)$.

\footnotetext{
${ }^{3}$ In our simple model, an optimal contract would be a franchise contract in which the financier pays the entrepreneur a fixed wage and is a residual claimant. This contract does not work in practice because it does not provide the entrepreneur the incentives to behave responsibly.
} 
If the project is not funded, the entrepreneur receives a payoff that we normalize to zero. If the project is funded, the entrepreneur incurs an opportunity cost of $\left(1+r_{i}\right) w$ for providing entrepreneurial capital. ${ }^{4}$ If the entrepreneur pursues his project then he can finance it with either debt or equity. With debt finance, the entrepreneur proposes the interest rate $r$; and with equity finance, the entrepreneur proposes the equity share $k$ that the financier would receive. If a debt contract with interest rate $r$ is used, the financier is a lender who receives $\min \{x+y,(1+r)(1-w)\}$, while the entrepreneur receives $x+y-\min \{x+y,(1+r)(1-w)\}$. If, instead, an equity contract with share $k$ is used, the financier is a venture capitalist who receives $k(x+y)$, while the entrepreneur receives $(1-k)(x+y)$.

If informed finance is pursued, the terms must provide the financier an ex ante payoff of at least $\bar{u} \geq 0$ net of information acquisition costs. We introduce $\bar{u}$ to capture the possibility that the financier has some market power and can extract rents. When $\bar{u}=0$, financial markets are perfectly competitive- the entrepreneur can play off potential investors against each other-in which case only the financier's opportunity cost of capital and investigation costs need be covered.

If the project is financed then these proposed terms or "term sheets" determine the funding conditions. This assumption captures standard industry practice (see Kaplan and Stromberg [17]). The term sheet is a summary of the terms and conditions that will apply if the venture capitalist and entrepreneur consummate their agreement. Obviously, funding is contingent on a positive project evaluation by the venture capitalist following his thorough investigation.

\section{Timing of Decisions.}

$\mathbf{t}=\mathbf{1}$ If the entrepreneur seeks finance then he proposes either a debt contract with interest rate $r$ or an equity contract with share $k$.

$\mathbf{t = 2}$ If finance is sought, the financier decides whether or not to investigate the project.

$\mathbf{t}=\mathbf{3}$ If the financier investigates the project at $t=2$, at the $\cos t c$ he learns the realization $x$ of $X$. The financier then decides whether to accept or reject the funding terms proposed by the entrepreneur.

$\mathbf{t}=\mathbf{4}$ If the project is funded, payoffs are realized and payments made according to the contract set at date one. If the project is not funded following an investigation, the entrepreneur's payoff is zero, and the financier's payoff is $-c$.

\footnotetext{
${ }^{4}$ For simplicity, we assume that the entrepreneur and financier share a common discount factor. Qualitatively, none of our findings depend on this assumption.
} 


\section{Equity Finance}

Suppose that the entrepreneur proposes equity terms that make it worthwhile for the venture capitalist to investigate. Then, given a proposed share $k$, the venture capitalist extends finance if and only if his expected payoff after learning $x$ exceeds his opportunity cost of providing funds, i.e.,

$$
E[k(x+Y)] \geq\left(1+r_{i}\right)(1-w) .
$$

Thus, funding is extended if and only if $x \geq x_{E}$, where

$$
x_{E}=\frac{\left(1+r_{i}\right)(1-w)}{k} .
$$

The entrepreneur understands that the share $k$ he offers the venture capitalist affects $x_{E}$, and hence the set of projects that the venture capitalist would fund. The entrepreneur also understands that the venture capitalist only investigates if it is in the venture capitalist's interest to do so. Therefore, if the entrepreneur seeks venture capital finance, the proposed equity share solves the following optimization problem.

\section{Problem 1}

$$
\max _{k \in[0,1]} P\left(\left\{X \geq x_{E}\right\}\right)\left(E\left[(1-k)(X+Y) \mid X \geq x_{E}\right]-w\left(1+r_{i}\right)\right) .
$$

subject to

$$
\begin{gathered}
P\left(\left\{X \geq x_{E}\right\}\right) E\left[k(X+Y)-\left(1+r_{i}\right)(1-w) \mid X \geq x_{E}\right]-c \geq \bar{u} ; \\
P\left(\left\{X \geq x_{E}\right\}\right) E\left[k(X+Y)-\left(1+r_{i}\right)(1-w) \mid X \geq x_{E}\right]-c \geq E\left[k(X+Y)-\left(1+r_{i}\right)(1-w)\right] .
\end{gathered}
$$

The objective is the entrepreneur's ex-ante expected payoff from a given share $k$. Funding is offered with probability $P\left(\left\{X \geq x_{E}\right\}\right)$, and $E\left[(1-k)(X+Y) \mid X \geq x_{E}\right]-w\left(1+r_{i}\right)$ is the entrepreneur's expected payoff from a funded project. Constraint (2) says that the venture capitalist's equity share $k$ must provide him a net expected payoff of at least $\bar{u}$. Constraint (3) says that it is in the venture capitalist's interest to investigate the project: the left-hand-side is his payoff from investigating, while the right-hand-side is his payoff from funding a project without an investigation.

We now show that under innocuous conditions, equity finance gives rise to under-financing. That is, the venture capitalist will not fund some projects that have a positive marginal social value. To increase the chance of funding, the entrepreneur willingly proposes to give the venture capitalist an equity share that generates a strictly positive return in excess of the venture capitalist's required return.

Proposition 1 If $c$ and $\bar{u}$ are not too large then constraints (2) and (3) of Problem 1 do not bind and there is under-financing i.e., $x_{E}>1+r_{i}$. 
The proof details the precise bounds on $c$ and $c+\bar{u}$ for the constraints to be slack, so that the venture capitalist's ex-ante expected profit strictly exceeds $\bar{u}$. Because the entrepreneur proposes the contract terms, one might expect that the entrepreneur would select a share that gives the venture capitalist only the minimum required return, $\bar{u}$. Proposition 1 shows that this is not the case. To understand why, recognize that from the point of view of the venture capitalist, the equity contract is a call option with strike price $x_{E}$ that he buys at a price equal to his investigation cost, $c$. This is because the venture capitalist provides funding if and only if $x \geq x_{E}$. The payoff of the option is always strictly positive. If $c$ and $\bar{u}$ are small, then for the venture capitalist not to receive a profit in excess of $\bar{u}$, the strike price $x_{E}$ must be close to the maximal project realization, which means that the option is almost never exercised. Rather than have a tiny chance of funding, the entrepreneur willingly cedes a larger share to the venture capitalist, raising $k$ above the venture capitalist's break-even point. This lowers the strike price $x_{E}$, which increases the entrepreneur's probability of being funded. However, increasing $k$ also transfers more surplus to the venture capitalist, particularly for outstanding projects. The optimal share trades off between these two factors.

To understand why under-investment occurs, note that it is socially efficient to fund any project with an expected return of at least $\left(1+r_{i}\right)$. But as long as the constraints do not bind, the entrepreneur never gives up all of the surplus so that his return strictly exceeds $w\left(1+r_{i}\right)$. The financier only funds a project if he expects a payoff that covers the opportunity cost of his funds $(1-w)\left(1+r_{i}\right)$. Adding, it follows that the expected payoff on the marginal project strictly exceeds $\left(1+r_{i}\right)$, which implies that there is under-financing.

Indeed, under-financing typically results even if $c+\bar{u}$ is large enough that the constraints bind. In particular, the financier breaks even on the marginal project gross of costs $c$, while the minimum-payment constraint 2 that determines $k$ reflects an average over all projects better than the marginal project. As long as $c+\bar{u}$ is not inordinately large, the entrepreneur's equity share $1-k$ exceeds the entrepreneurial capital investment $w$. As a result, the marginal project has a strictly positive NPV. Our empirical analysis will reveal that for relevant parameterizations both constraints of Problem 1 are slack.

\section{Debt Finance}

Now suppose that the entrepreneur proposes debt finance terms that make it worthwhile for a lender to investigate the project. As with informed equity, the lender offers funding after learning realization $x$ if and only if he expects to cover his opportunity cost of funds, $\left(1+r_{i}\right)(1-w)$. Formally, a lender extends funding if and only if $x \geq x_{D}$, where $x_{D}$ solves

$$
E\left[\min \left\{x_{D}+Y,(1+r)(1-w)\right\}\right]=\left(1+r_{i}\right)(1-w) .
$$

The interest rate, $r$, offered by the entrepreneur therefore solves the following optimization problem: 


\section{Problem 2}

$$
\max _{r} P\left(\left\{X \geq x_{D}\right\}\right)\left(E\left[X+Y-\min \{X+Y,(1+r)(1-w)\} \mid X \geq x_{D}\right]-w\left(1+r_{i}\right)\right)
$$

subject to

$$
\begin{aligned}
& P\left(\left\{X \geq x_{D}\right\}\right) E\left[\min \{X+Y,(1+r)(1-w)\}-\left(1+r_{i}\right)(1-w) \mid X \geq x_{D}\right]-c \geq \bar{u} \\
& P\left(\left\{X \geq x_{D}\right\}\right) E\left[\min \{X+Y,(1+r)(1-w)\}-\left(1+r_{i}\right)(1-w) \mid X \geq x_{D}\right]-c \\
& \geq E\left[\min \{X+Y,(1+r)(1-w)\}-\left(1+r_{i}\right)(1-w)\right] .
\end{aligned}
$$

The objective is the entrepreneur's ex-ante expected payoff from a given interest rate $r$. The interest rate has two effects on the entrepreneur's payoff. The interest rate directly affects the amount of money, $\min \{x+$ $Y,(1+r)(1-w)\}$, that the entrepreneur must repay. The interest rate also indirectly affects payoffs through its impact on the marginal-project funded, $x_{D}$, and hence on the funding probability, $P\left(\left\{X \geq x_{D}\right\}\right)$.

Constraints (5) and (6) are analogues of constraints (2) and (3) in problem 1. Constraint (5) ensures that the informed lender's expected payoff net of his investigation $\cos t c$ is at least $\bar{u}$. Constraint (6) ensures that it is optimal for the lender to investigate the project.

We now provide conditions under which debt gives rise to over-financing. That is, with debt, an informed lender extends funding to negative NPV projects. While the lender expects to cover his capital costs on these projects, the founders and key personnel do not expect to cover their entrepreneurial capital investment $\left(1+r_{i}\right) w$, and hence would prefer not to have these negative NPV projects funded.

Proposition 2 Suppose that $Y$ has support $[\underline{y}, \bar{y}]$. Then a sufficient condition for informed debt to give rise to over-financing, i.e. $x_{D}<1+r_{i}$, is that $-\underline{y}<w\left(1+r_{i}\right)$. In this instance, an informed lender funds negative NPV projects that the entrepreneur would prefer to remain unfunded.

To understand why debt can give rise to over-financing, suppose that the lender can evaluate a project perfectly, i.e., $Y \equiv 0$. Then equation (4) immediately implies that $x_{D}=\left(1+r_{i}\right)(1-w)<\left(1+r_{i}\right)$, so that projects with payoffs $E[x+Y] \in\left[\left(1+r_{i}\right)(1-w),\left(1+r_{i}\right)\right]$ are funded to the entrepreneur's detriment- the lender does not internalize the fact that project payoffs may only partially compensate key personnel for their entrepreneurial capital. As a consequence, some projects that have a negative NPV after accounting for entrepreneurial capital are funded. If, instead, $Y$ is non-degenerate so that there is project uncertainty that the lender cannot resolve, the lender will be more cautious in his lending decisions, increasing $x_{D}$ and reducing the over-financing. However, unless the unresolved uncertainty is quite large or $w$ is very small, it is still the case that $x_{D}<\left(1+r_{i}\right)$. 
We next show that to reduce this over-financing, the entrepreneur selects an interest rate that provides the lender his minimum required payoff, $\bar{u}$.

Proposition 3 Suppose that informed debt gives rise to over-financing. Then if the entrepreneur pursues debt finance, he chooses the interest rate that gives the lender an expected payoff net of his investigation costs of $\bar{u}$.

The intuition is simple. Reducing $r$ both reduces the entrepreneur's payment to the investor, and decreases over-financing by increasing $x_{D}$. As a result, the entrepreneur chooses $r$ as low as possible, so that the lender receives $\bar{u}$. We next show that increasing the intrinsic uncertainty that is not resolved by a lender's project evaluation, reduces the magnitude of over-financing.

Proposition 4 Let $Y$ be a mean-preserving spread of $\tilde{Y}$. Suppose that informed debt gives rise to overfinancing when the unresolved uncertainty is $Y$. Then, raising the unresolved uncertainty from $\tilde{Y}$ to $Y$ reduces over-financing (i.e., raises $x_{D}$ ), and raises both the entrepreneur's payoff and the interest rate.

Due to the concavity of the debt function, the lender responds to increased unresolved uncertainty about a project by funding fewer negative NPV projects. Because over-financing is reduced and both parties are risk neutral, it follows that adding mean zero uncertainty makes the entrepreneur better off. If, instead, we fix the total project uncertainty, and increase the unresolved uncertainty, then, in general, the entrepreneur is made worse off, as the lender learns less from his investigation. For example, if $X \equiv E[X]$ and $Y$ contains all project uncertainty, then investigating the project is pointless, and the entrepreneur is worse off relative to a situation in which information about the project can be acquired.

Next, we detail how over-financing is affected by key parameters of the economy.

Proposition 5 Suppose that informed debt gives rise to over-financing. Then the following parameter changes reduce the quality of the marginal-funded project, $x_{D}$, and hence raise over-financing:

1. reducing the risk adjusted rate of interest, $r_{i}$;

2. increasing the entrepreneurial capital, $w$;

3. increasing the cost of investigation, $c$;

4. increasing the lender's bargaining strength, $\bar{u}$.

Reducing $r_{i}$ lowers the lender's opportunity costs of funds, which raises the attractiveness of funding any project. As a consequence, the marginal funded project must have a lower return, which means that $x_{D}$ falls. 
Similarly, raising entrepreneurial capital $w$ raises over-financing, because the lender does not internalize $w$ in his funding decision. Both raising $\bar{u}$ and raising $c$ increase the equilibrium interest rate that the lender receives, making him more willing to fund marginal projects.

\subsection{Debt versus Equity}

Propositions 1 and 2 raise the following questions: when would the entrepreneur prefer informed debt finance, and when would venture capital finance be more attractive? Qualitatively, the answer is clear. If there is substantial probability mass on marginally negative NPV projects, $x \in\left[x_{D},\left(1+r_{i}\right)\right]$, then informed debt finance gives rise to significant over-financing, making venture capital more attractive. Analogously, if there is substantial probability mass on projects $x \in\left[\left(1+r_{i}\right), x_{E}\right]$, i.e., if many projects are small positive NPV projects, then informed equity finance gives rise to significant under-financing, which makes debt more attractive. Finally, if projects are likely to have a positive ex-ante NPV and investigation costs are large relative to the capital required for finance, then it may be optimal to pursue uninformed finance.

Lastly, we observe that our theoretical model of debt abstracts from bankruptcy and other enforcement costs, as well as restrictions imposed on institutional lenders about their portfolio risks (e.g., CAMEL ratings for banks). For example, if a project is very risky, then debt finance may require very high interest rates, resulting in enormous default rates. In our empirical analysis, we quantify these risks for projects that are candidates for venture capital finance.

\section{Empirical Analysis}

\subsection{Overview}

There are core goals of this section. First, we want to understand how well our model explains the quantitative empirical regularities of venture capital finance. We then want to use the estimates of the primitive parameters of our model to gain insights into the "ex-ante" properties of projects that may be targets for venture capital. In particular, we want to derive the extent to which a venture capitalist's investigation (i) increases the mean of funded relative to unfunded projects, and (ii) reduces uncertainty about project payoffs; and the extent to which venture capitalists underfund projects relative to the social optimum. We also want to obtain measures of the surplus associated with these entrepreneurial projects, the share accruing to venture capitalists (after accounting for investigation costs), and to understand why these projects receive equity rather than debt finance.

We first identify five key empirical moments of venture capital finance- the venture capitalist's equity share, the mean and standard deviation of the venture capitalist's returns from funded projects, the probabil- 
ity that a project is funded, and the probability that the venture capitalist loses money.

The primitive specifications of the model - the distributions $X$ and $Y$ of project payoffs together with entrepreneurial capital $w$ and the risk-adjusted interest rate $r_{i}$ - endogenously generate these five moments. We identify $r_{i}$ from the data, leaving $X, Y$ and $w$ to be specified. To minimize the free parameters at our disposal, we assume that $X$ follows a lognormal distribution, and $Y$ a normal distribution. The assumption that $X$ is log-normally distributed captures both the long upper tail and the thick lower end of the distribution of project payoffs; and the normality of $Y$ imposes symmetry on the error in a venture capitalist's evaluation. This gives us four primitive parameters to match the five endogenous empirical moments: The mean $\mu$ and the standard deviation $\sigma_{X}$ of $\ln (X) ;^{5}$ the standard deviation $\sigma_{Y}$ of $Y$ (recall that $Y$ has mean zero), and entrepreneurial capital $w$. Note that we focus on empirical moments that are relatively insensitive to the tail properties of $X$ and $Y$, and hence are relatively robust to distributional assumptions.

Our estimation procedure identifies the four primitive parameters that best fit the data. Using the sup norm distance metric, we choose $w, \mu, \sigma_{X}$ and $\sigma_{Y}$ to minimize the percentage difference between the predicted and empirical values for the five endogenous moments. We find that at the optimized values of the primitive parameters, the percentage differences between the empirical moments and their predicted values are extremely small. One may then raise the following questions:

- Can the model fit "literally everything”, or does the model's economic structure drive the good fit?

- What is the quality of our estimates of the primitive parameters characterizing entrepreneurial projects, given that there may be substantial noise in the estimates of the empirical moments?

We document in two ways that it is the economic structure that underlies the fit. Most basically, note that it is not typically possible to solve five equations with only four unknowns. We then perturb the empirical moments away from their estimated values, and show that the model's fit is distinctly less good. This analysis also reveals how predicted moments are affected by changes in the primitives, permitting us to uncover the driving forces underlying our point estimates.

It is also important to recognize that there may be errors in the point estimates of the empirical moments and of $r_{i}$. To account for this noise, we assume that the true empirical moments and $r_{i}$ are drawn from normal distributions with means equal to their point estimates, and standard deviations equal to $10 \%$ of the associated point estimates (i.e., the $95 \%$ confidence interval is approximately $\pm 20 \%$ ). We then do a Monte Carlo analysis. Drawing 5,000 samples of "empirical moments" and calculating the primitive parameters that best fit those sampled moments, we determine the $95 \%$ confidence intervals for each primitive param-

\footnotetext{
${ }^{5}$ The mean of $X$ is $e^{\mu+0.5 \sigma_{X}^{2}}$ and its variance is $e^{2 \mu+2 \sigma_{X}^{2}}-e^{2 \mu+\sigma_{X}^{2}}$. The median $m$ of $X$ is $e^{\mu}$.
} 
eter. Despite the wide range from which the empirical moments are drawn, these confidence intervals are relatively tight. This indicates that we can be confident in our point estimates of the primitive parameters.

\subsection{Description of empirical moments}

We now detail how we derive the various moments and $r_{i}$ from the data.

VC's equity share: Kaplan and Stromberg [18] have a data set with 213 investments by 14 venture capital firms. The data include the contractual agreements governing each financing round in which the firm participated. In practice, the venture capitalist's share is contingent on performance: if the firm does well, then the founders receive stock options that dilute the venture capitalist's share. Kaplan and Stromberg find a median minimum share of $41 \%$ for first round finance (i.e., the share the venture capitalist receives when the firm meets all performance standards), and a median maximum share of 50.5\% for first round finance. Because the venture capitalist's share is less when the firm does well, this suggests an average venture capital share of $43-44 \%$. Although venture capital contracts are only approximately linear, ${ }^{6}$ our abstraction of a perfectly linear contract closely mirrors the data.

Mean VC Return: Ljungqvist and Richardson [19] have a data set containing the exact timing of investments and distribution of cash flows for 73 private equity funds, of which 19 are venture capital funds. This data set is free of the sample selection bias that Cochrane [9] must address. Ljungqvist and Richardson find that the risk-adjusted return with respect to the ex-ante cost of capital is $28 \%$ for venture capital funds.

Standard Deviation of VC return: Cochrane [9] computes the standard deviation of the financier's return per unit capital invested for different financing rounds. His estimated standard deviation for the first round of finance, which is the appropriate measure for our model, is $120 \%$. This is slightly higher than the standard deviation across all rounds of funding which is 107\%. Peng Chen, Gary Baierl and Paul Kaplan [8] find a slightly higher standard deviation over all rounds of finance of $116 \%$.

Probability of Funding: There are essentially two stages of evaluation for first-stage funding. In the first stage, the venture capitalist does a cursory (few minute) skim of the abstract of the business plan, discarding the overwhelming majority. The remaining projects receive serious scrutiny-and this is the investigation that we model. Blumberg Capital (http://www.sba.gov/INV/vc101.pdf) asserts that "a typical $\$ 100$ million venture capital firm receives at least 1,500 business plans per year. Perhaps 50 result in serious due diligence, and 5 ultimately will obtain funding." Sherman McCorkle, CEO of Technology Venture Corporation asserts that about $10 \%$ of all projects that are subjects of detailed investigations are funded (http://www.abqtrib.com/archives/business00/050100_tvcsymp.shtml). Other informal sources also suggest

\footnotetext{
${ }^{6}$ It is worth noting that this limited non-linearity slightly reduces the venture capitalist's returns both by lowering their claims to the best projects and by reducing the inefficiency in funding decisions associated with pure equity contracts.
} 
a rate of about $10 \%$ or slightly higher. ${ }^{7}$

Risk-adjusted interest rate, $\boldsymbol{r}_{i}$ : Ljungqvist and Richardson [19] estimate $\beta=1.12$ for venture capital funds. As the risk-free rate, they use the interest rate on 10 year treasury notes in the month the fund was raised, which averaged $9.2 \%$ over the relevant time period, which exceeds by about $2.1 \%$ the return on 3 month T-bills. Mehra and Prescott [20] document that the equity premium $r_{m}-r_{f}$ is $6 \%$, where $r_{f}$ is the interest on short term treasury bills. Assuming an expected equity premium of $4 \%$ over 10 year treasuries, yields a risk-adjusted interest rate of 13.8 percent, which we use for $r_{i}$.

Probability VC loses money: The probability the venture capitalist loses money equals the probability that his return is less than $1+r_{i}$. Using Cochrane's data set we compute the loss probability for venture capital projects with a first round of finance between 1987 and 1992. Cochrane's data set extends to 2000_by using this earlier sample we ensure that more uncertainty about project returns is resolved. 33 percent of these firms went public with IPOs, 35 percent were acquired by another firm, 19 percent went out of business and only 13 percent remained private by the year 2000. Return data are obviously unavailable for firms that remain private, and they are also lacking for about half of IPOs and acquisitions. For those for which we have data, including negative and zero returns for IPOs, 16.8 percent of IPOs lose money; $33.6 \%$ percent of acquisitions lose money; and presumably all bankrupt firms lose money. The final issue is how to evaluate privately-held firms. These privately-held firms have been active for a minimum of 7 years, so they are not clearly lemons. If privately-held firms are as likely as acquired projects to lose money, then $40.6 \%$ of all projects fail to earn the venture capitalist's required return of 13.8 percent. This estimate of $40.6 \%$ is not substantially affected by changes in $r_{i}$ or by alternative ways of accounting for the missing data.

\subsection{Results}

Inspection of Table 1 reveals that at the optimized levels of the four primitive parameters, the model does an astonishingly good job of matching the five key empirical moments characterizing venture capital finance. None of the five predicted moments differs by more than $0.6 \%$ from their empirical counterparts. ${ }^{8}$

In particular, we can explain all of the venture capitalist's excess return, without having to appeal to an illiquidity premium, or to market power for venture capitalists, or more generally to other market imperfec-

\footnotetext{
${ }^{7}$ Our assumption that only one venture capitalist seriously investigates a given project approximates practice. While rejection at the first stage may not reflect on the project's intrinsic merit, "Once a [project] is rejected [after serious scrutiny], it is very difficult to get it reconsidered... if the proposal is rejected... it may get an 'overshopped' reputation. Venture capitalists trade information quite freely and a turndown by one firm influences others" (Paul Keaton, http://www.i2m.org/ftp/freepubs/0501.pdf). If one could eliminate firms from the sample that were rejected after serious scrutiny, one would get a higher acceptance probability, which is consistent with our numerical analysis. Indeed, for reasonable distributional and investigation cost assumptions in our model, it is not optimal for an entrepreneur to consider a two-stage strategy in which he offers a higher equity share to a venture capitalist on the second round if rejected in the first round. This is because a first-round rejection precludes a high upside for the project, and the share must compensate the second-round venture capitalist for his investigation given the project's lower potential.

${ }^{8}$ The high quality of the fit indicates that our estimates are insensitive to the distance metric that we use.
} 


\begin{tabular}{|c|c|c|c|c|c|}
\hline & $k$ & return & stdv return & prob fund & prob loss \\
\hline $\begin{array}{l}\text { empirical } \\
\text { values }\end{array}$ & $43.5 \%$ & $28.0 \%$ & $120.0 \%$ & $10.0 \%$ & $40.6 \%$ \\
\hline $\begin{array}{l}\text { prealcted } \\
\text { values }\end{array}$ & $43.3 \%$ & $28.2 \%$ & $119.3 \%$ & $10.0 \%$ & $40.8 \%$ \\
\hline
\end{tabular}

tions. That is, the entrepreneur willingly gives the venture capitalist an equity share sufficient to generate substantial "excess" returns. The entrepreneur does this to mitigate the severe under-investment problem, i.e., to increase his chances of being funded. Even with this premium, our model predicts that venture capitalists fail to fund about 60 percent of all projects that have positive NPV s conditional on their investigation. ${ }^{9}$ Consistent with this prediction, 81 percent of surveyed venture capitalists felt that a significant number of viable early-stage investments go unfunded (Meyer et al. [21]).

Table 2: Estimated Exogenous Parameters of Entrepreneurial Projects

\begin{tabular}{||l|ccccc||}
\hline \hline & $w$ & $\operatorname{median}_{X}$ & $\sigma_{X}$ & $\sigma_{Y}$ & $\begin{array}{l}\text { \% uncertainty } \\
\text { resolved }\end{array}$ \\
\hline \hline $\begin{array}{l}\text { value } \\
\begin{array}{l}95 \% \text { conf } \\
\text { interval }\end{array}\end{array}$ & 0.500 & 0.756 & 0.431 & 1.337 & $27.0 \%$ \\
\hline \hline
\end{tabular}

Table 2 provides the estimates for the primitive parameters and their $95 \%$ confidence intervals. As explained in the overview, it is important to recognize that the empirical moments and our estimate of $r_{i}$ are in fact random variables derived from estimation processes. To determine confidence intervals, we draw 5,000 independent samples assuming that the empirical moments and $r_{i}$ are drawn from normal distributions with standard deviations equal to $10 \%$ of the point estimates. Except for $\sigma_{Y}$, the confidence intervals on the primitive parameters are distinctly narrower than their counterparts for the empirical moments. Finally, the last column shows the percentage by which the venture capitalist reduces the standard deviation of the ex-ante project's payoff through his investigation, i.e., it captures the percentage of uncertainty resolved. ${ }^{10}$

Economic Interpretation. We first emphasize that the estimates of these primitive parameters make significant economic sense. Most obviously, founders and key personnel must contribute significant entrepreneurial capital $w$, else the venture capitalist would require a share that exceeds the observed range of $k$. Similarly, $w$ cannot be too large, else either $k$ would fall short of the observed range; or with $k$ in the

\footnotetext{
${ }^{9}$ Again we note that these predictions are not affected by the venture capitalist's cost of investigation $c$, as long as their "excess returns" cover $c$.

${ }^{10}$ Of course, after the investigation, the venture capitalist will not fund most projects, so that the standard deviation of funded projects differs substantially from that for ex-ante projects.
} 
observed range together with a small contribution $1-w$ by the venture capitalist, the venture capitalist's return would be too high. That is, $(1-w) / k$ cannot deviate too far from 1 , and $w$ should therefore be in the range indicated by the confidence band. It is worth noting that the width of the confidence interval for $w$ is driven solely by the generous range of uncertainty that we allow for $k$ : if we reduce the standard deviation of $k$ to $5 \%$, then the confidence interval for $w$ reduces to [.446, .558], while confidence intervals for all other primitive parameters are affected by less than 0.004 .

We next observe that the low funding rate of $10 \%$ indicates that the unconditional expected project NPV must be significantly negative-most projects must be losers. The negative return is also indicated by the fact that even after eliminating the bottom $90 \%$ of projects, $40.6 \%$ of funded projects still lose money. One might conjecture that these observations imply an extremely negative ex-ante NPV. However, this conjecture fails to account for the significant underfinancing of entrepreneurial projects (Meyer et al. [21]) — there are rejected projects with positive expected NPVs after a venture capitalist's investigation. It follows that the ex-ante NPV must be negative, but not too negative. The estimate of the ex-ante median project payoff of $-25 \%$ (the mean is $-19 \%$ ) reflects these considerations. The especially tight confidence interval emphasizes the robustness of these arguments.

Finally, given the low median of the ex-ante project, in order to generate the $28 \%$ excess return for a venture capitalist, there must be significant uncertainty for a venture capitalist's investigation to resolve, i.e., $\sigma_{X}$ must be substantial. In addition, $\sigma_{Y}$ must be large relative to $\sigma_{X}$ to account for the high frequency of ex-post mistakes that the venture capitalist makes, i.e., to account for the $40.6 \%$ of funded projects that lose money. Finally, $\sigma_{Y}$ cannot be too large, else the standard deviation of the venture capitalist's return would exceed its empirical counterpart.

Goodness of fit. We now show that if some of the empirical moments are changed significantly from their point estimates, the model fit deteriorates substantially. We perturb the empirical moments separately, considering $40 \%$ deviations in each direction away from their point estimates, moving them outside their confidence intervals. We then solve for the primitive parameters that provide the best fit.

Table 3: Goodness of Model Fit

\begin{tabular}{||l|ccccl||}
\hline \hline $\begin{array}{l}\text { perturbed } \\
\text { variable }\end{array}$ & $w$ & $\operatorname{median}_{X}$ & $\sigma_{X}$ & $\sigma_{Y}$ & \multicolumn{1}{c|}{$\begin{array}{l}\text { maximum } \% \\
\text { difference }\end{array}$} \\
\hline \hline $\begin{array}{l}\text { prob loss: }-40 \% \text { to }+40 \% \\
\text { stdv: }-40 \% \text { to }+40 \%\end{array}$ & $.526-.442$ & $.745-.769$ & $.520-.363$ & $.830-1.661$ & $33.4 \%-22.2 \%$ \\
return: $-40 \%$ to $+40 \%$ & $.509-.524$ & $.756-.754$ & $.406-.444$ & $.833-1.855$ & $8.1 \%-5.7 \%$ \\
prob fund: $-40 \%$ to $+40 \%$ & $.559-.475$ & $.859-.677$ & $.291-.546$ & $1.192-1.452$ & $7.4 \%-4.8 \%$ \\
$k:-40 \%$ to $+40 \%$ & $.715-.247$ & $.712-.805$ & $.431-.431$ & $1.260-1.429$ & $.6 \%-.6 \%$ \\
\hline \hline
\end{tabular}


Note that because we match the point estimates so closely, slight perturbations cannot alter the fit significantly. For example, if we move one empirical moment by $x \%$ then all primitive parameters will adjust, resulting in a model fit that is better than $x \%$. Table 3 presents how the moment perturbations affect the estimates of the primitive parameters. The last column shows the maximum percentage difference between the predicted and empirical/perturbed moments. Note that a maximum difference of $y \%$ indicates that at least two of the predicted moments differ from their empirical counterparts by $y \%$. Table 3 reveals that except for share $k$ and the probability of funding, all deviations from the point estimates lead to worse model fits. The model is most sensitive to misspecification of the probability that the venture capitalist loses money: logically, the symmetry of the distribution of $Y$ implies that the model can never generate failure rates exceeding 50\%. More surprisingly, the model cannot fit failure rates that are too low: low failure rates demand a low $\sigma_{Y}$, but a low $\sigma_{Y}$ results in a standard deviation of the venture capitalist's return that is far too low.

Heterogeneity in project characteristics. The point estimates derived above describe the "typical" venture capital project. In practice, there is likely heterogeneity in ex-ante project characteristics. For example, the founders for one project may provide more entrepreneurial capital than founders of other projects. One would expect that the venture capitalist's share would be smaller when founders provide more inputs. Consequently, one wants to understand how heterogeneity in $w$ and the other primitive parameters affect the contract terms, $k$, and the other moments associated with venture capital finance.

Table 4: Project Heterogeneity

\begin{tabular}{||l|ccccc||}
\hline \hline $\begin{array}{l}\text { perturbed } \\
\text { variable }\end{array}$ & $\% \Delta k$ & $\% \Delta$ return & $\% \Delta$ stdv & $\% \Delta$ prob fund & $\% \Delta$ prob loss \\
\hline \hline & & & & \\
$w:-10 \%$ to $+10 \%$ & +8.8 to -9.0 & -1.1 to +1.1 & -1.1 to +1.2 & -4.5 to +4.8 & 0.0 to 0.0 \\
$m:-10 \%$ to $+10 \%$ & +1.4 to -1.5 & -8.2 to +8.3 & +0.9 to -0.9 & -32.3 to +36.7 & +2.0 to -2.0 \\
$\sigma_{X}:-10 \%$ to $+10 \%$ & +2.2 to -2.2 & -14.9 to +15.7 & +1.2 to -1.0 & -14.4 to +12.6 & +3.4 to -3.6 \\
$\sigma_{Y}:-10 \%$ to $+10 \%$ & 0.0 to 0.0 & 0.0 to 0.0 & -9.3 to +9.1 & 0.0 to 0.0 & -2.2 to +1.9 \\
$r_{i}:-10 \%$ to $+10 \%$ & -0.2 to +0.2 & -0.2 to +0.2 & -0.2 to +0.2 & +4.3 to -4.1 & 0.0 to 0.0 \\
\hline \hline
\end{tabular}

Table 4 reveals that many of the key moments of venture capital finance are not that sensitive to heterogeneity in project characteristics. Most surprisingly, the interest rate has only a moderate impact on the probability of funding, but has no significant influence on all other parameters. This insensitivity is most surprising for the excess return, which is the gross return minus $r_{i}$ : this result reflects the fact that the gross return increases at the same rate as $r_{i}$ due to the reduction in the funding probability. Of the moments that are affected, note first that raising the median project payoff or its upside potential (via $\sigma_{X}$ ) has the anticipated effect on the return, but also has a surprisingly strong impact on the funding probability. That is, an entrepreneur whose ex-ante project stands out even slightly among its peers can vastly increase the probability 
of getting funding. Finally, $w$ and $k$ move almost one-for-one with each other for the reasons that we have already highlighted.

Model Implications. We have shown that our theoretical model robustly generates the key empirical regularities in the data. This is important in its own right. As important, it indicates that the model's predictions can be used to obtain insights into moments for which it is infeasible to gather data. We have already gained such quantitative measures for the primitive parameters of entrepreneurial finance. We now present additional implications of those parameters.

We first compare the properties of funded and unfunded projects. Our primitive parameter estimates imply that if a venture capitalist funded all projects, then $57.2 \%$ would have negative NPVs. The venture capitalist's investigation lowers this number for funded projects to $36.0 \% .{ }^{11}$ By eliminating likely losers, a venture capitalist's investigation dramatically raises the expected project return from $-17.0 \%$ to $63.7 \%$. Remarkably, the standard deviation of the project's payoff is virtually unaffected: the unconditional standard deviation of the project's return is $138.8 \%$, while it is $137.6 \%$ for funded projects. ${ }^{12}$ The reason that eliminating likely losers does not lower the standard deviation is that this filtering eliminates the thick bottom tail of the lognormal distribution, leaving the long (high variance) upper tail.

We can also compute the project's ex-ante expected surplus, given measures of the costs of investigation, Total surplus is the sum of the entrepreneur's and venture capitalist's surplus,

$$
P\left(\left\{X \geq x_{E}\right\}\right) E\left[(1-k) X-w\left(1+r_{i}\right) \mid X \geq x_{E}\right]+P\left(\left\{X \geq x_{E}\right\}\right) E\left[k X-(1-w)\left(1+r_{i}\right) \mid X \geq x_{E}\right]-c
$$

where $x_{E}$ is the cutoff for finance. Our primitive parameter estimates yield ex-ante expected surplus of 0.036 for the entrepreneur, and surplus of $0.014-c$ for the venture capitalist. Ex-ante surplus is low simply because only one project in ten is funded. To determine approximate levels of investigation costs, we note that a venture capitalist's inputs to a funded project on an annual basis are about $\$ 2$ million (including the value of their time providing advice to the entrepreneur). If investigation costs are about $\$ 10,000$ per investigated project, then $c=0.005$. For such a value of $c$, a venture capitalist expects to extract $20 \%$ of the total project surplus, which is a large percentage for the entrepreneur to cede to venture capitalists. Anecdotal evidence indicates that even though this is optimal, entrepreneurs still resent having to give up so much, as they provide the key idea and technical expertise, and the venture capitalist "just" provides the money and business advice.

Our relatively low estimate of the total surplus suggests that the surplus from rejected projects is likely negative. This observation can reconcile the reluctance of venture capitalists to investigate projects that were rejected after serious scrutiny by other financiers, and it also indicates why venture capitalists only consider projects with significant upside potential.

\footnotetext{
${ }^{11}$ Because $\frac{k}{1-w}<1$, the probability a venture capitalist loses money is slightly higher than $36.0 \%$.

${ }^{12}$ The standard deviation for the venture capitalist is damped slightly because $\frac{k}{1-w}<1$.
} 
Finally, we consider the question of why debt finance is not pursued by the types of projects identified by our analysis. Using the primitive parameters describing the ex-ante project, we can compute the interest rate that a lender would have to receive just to break even. We find that even if investigation costs were zero, the interest rate would have to exceed $80 \%$ and the corresponding default rate would exceed 35\%-even with trivial bankruptcy costs, expected default costs would be large. Bank regulation in the United States certainly precludes banks from providing loans with such high default rates and it is likely that such high interest rates would not be enforced by a court. It seems clear therefore that debt finance is feasible only for far safer projects.

\section{Conclusion}

This paper develops the simple analytical implications of informed finance: equity gives rise to underfinancing, while debt gives rise to over-financing of safer projects because lenders do not internalize entrepreneurial capital of key personnel in the firm. Our quantitative analysis indicates that equity finance gives rise to significant under-financing: venture capitalists do not fund about 60 percent of all projects that have positive NPVs following a venture capitalist's investigation. To reduce this under-financing and increase the chances of funding, entrepreneurs willingly cede large equity shares to venture capitalists. Our quantitative analysis indicates that the excess returns that venture capitalists receive (see Ljungqvist and Richardson [19]) is due to the optimal decision by entrepreneurs to reduce the extent of under-financing.

More generally, our empirical analysis reveals that our model closely predicts the key statistics associated with venture capital finance in the United States. Our model's explanatory power indicates that one must take seriously the model's predictions about parameters that cannot be readily identified from the data. For example, our model indicates that venture capitalists are very successful at eliminating likely losers (projects with negative expected NPVs). Simply by eliminating losers, venture capitalists greatly raise expected returns of funded projects, even though the standard deviations of funded and unfunded project are virtually the same. Our empirical analysis also reveals that projects that are potential targets of venture capital finance are too risky for debt finance from formal lending sources. 


\section{Appendix}

Proof of Proposition 1. Let $[\underline{x}, \bar{x}]$ be the (possibly unbounded) support of $X$. Let $k^{*}$ be the solution to Problem 1 ignoring the constraints. Let $x_{E}^{*}=(1-w)\left(1+r_{i}\right) / k^{*}$ be the cutoff value for funding. Note that $x_{E}^{*}<\bar{x}$. Otherwise, no project is funded, and the entrepreneur's payoff is zero. Because the density $f(x)$ is strictly positive, the definition of $x_{E}^{*}$ immediately implies that

$$
\gamma_{1}=\int_{x_{E}^{*}}^{\bar{x}}\left[k^{*} x-\left(1+r_{i}\right)(1-w)\right] d F(x)>0,
$$

Similarly,

$$
\gamma_{2}=\int_{x_{E}^{*}}^{\bar{x}}\left[k^{*} x-\left(1+r_{i}\right)(1-w)\right] d F(x)-\int_{\underline{x}}^{\bar{x}}\left[k^{*} x-\left(1+r_{i}\right)(1-w)\right] d F(x)>0 .
$$

Then the constraints to Problem 1 are slack if and only if $c+\bar{u} \leq \gamma_{1}$ and $c \leq \gamma_{2}$.

Now suppose that the constraints are slack. Then the first-order condition to Problem 1 is

$$
-\int_{x_{E}^{*}}^{\bar{x}} x d F(x)+x_{E}^{*} f\left(x_{E}^{*}\right)\left[\frac{1-k^{*}}{k^{*}} x_{E}^{*}-\frac{w\left(1+r_{i}\right)}{k^{*}}\right]=0,
$$

Because $x_{E}^{*}<\bar{x}$ and $f(x)>0$ for $x \in[\underline{x}, \bar{x}]$ it follows that $-\int_{x_{E}^{*}}^{\bar{x}} x d F(x)<0$. Thus, $x_{E}^{*} f\left(x_{E}^{*}\right)>0$ and (9) imply

$$
\left(1-k^{*}\right) x_{E}>w\left(1+r_{i}\right) .
$$

Adding equation $k^{*} x_{E}=(1-w)\left(1+r_{i}\right)$ to $(10)$ yields $x_{E}^{*}>1+r_{i}$, i.e., there is under-financing.

Proof of Proposition 2. If $x \geq\left(1+r_{i}\right)(1-w)-\underline{y}$ then $E[\min \{x+Y,(1+r)(1-w)\}] \geq\left(1+r_{i}\right)(1-w)$ (since $r>r_{i}$, as the financier must recover costs $\left.c\right)$. Hence, $x_{D} \leq\left(1+r_{i}\right)(1-w)-\underline{y}$. Because $-\underline{y}<w\left(1+r_{i}\right)$, we get $x_{D}<1+r_{i}$, i.e., there is over-financing.

Proof of Proposition 3. Suppose that constraint (5) is slack and $x_{D}<1+r_{i}$. Now decrease $r$ marginally to $r^{\prime}$. Then equation (4) implies that $x_{D}$ increases marginally to $x_{D}^{\prime}$, such that $x_{D}^{\prime}<1+r_{i}$. Let $x \in\left[x_{D}, x_{D}^{\prime}\right]$. Then equation 4 implies $E[\min \{x+Y,(1+r)(1-w))\}] \geq\left(1+r_{i}\right)(1-w)$. Because $x_{D}^{\prime}<1+r_{i}$ it follows that $E[x+Y-\min \{x+Y,(1+r)(1-w)\}]-w\left(1+r_{i}\right)<0$ for all $x \in\left[x_{D}, x_{D}^{\prime}\right]$. Thus, the objective of problem 2 is increased if projects are not funded for which $x \in\left[x_{D}, x_{D}^{\prime}\right]$. If the interest rate is $r^{\prime}$ then only projects with $x \geq x_{D}^{\prime}$ are funded. This, and $r^{\prime}>r$ implies that the objective of problem 2 is strictly increased. 
It remains to prove that constraint (6) is satisfied. Note that

$$
\begin{aligned}
E[\min \{X+Y, & \left.(1+r)(1-w)\}-\left(1+r_{i}\right)(1-w)\right] \\
=P(X< & \left.x_{D}\right) E\left[\min \{X+Y,(1+r)(1-w)\}-\left(1+r_{i}\right)(1-w) \mid X<x_{D}\right] \\
& +P\left(X \geq x_{D}\right) E\left[\min \{X+Y,(1+r)(1-w)\}-\left(1+r_{i}\right)(1-w) \mid X \geq x_{D}\right]
\end{aligned}
$$

Subtracting $P\left(\left\{X \geq x_{D}\right\}\right) E\left[\min \{X+Y,(1+r)(1-w)\}-\left(1+r_{i}\right)(1-w) \mid X \geq x_{D}\right]$ on both sides of (6) and using (11) implies

$$
-c \geq P\left(X<x_{D}\right) E\left[\min \{X+Y,(1+r)(1-w)\}-\left(1+r_{i}\right)(1-w) \mid X<x_{D}\right] .
$$

When $r$ is decreased to $r^{\prime}$ then $E\left[\min \{X+Y,(1+r)(1-w)\}-\left(1+r_{i}\right)(1-w) \mid X<x_{D}\right]$ is decreased Moreover, $E\left[\min \left\{X+Y, 1+r^{\prime}\right\}-\left(1+r_{i}\right)(1-w) \mid X<x_{D}^{\prime}\right]<0$ for all $x \leq x_{D}^{\prime}$. Thus the increase of $x_{D}$ to $x_{D}^{\prime}$ further decreases the right-hand side of (12). Thus, constraint (6) is satisfied.

Proof of Proposition 4. By the the definition of second order stochastic dominance, $E[u(\tilde{Y})] \geq E[u(Y)]$ for any non-decreasing concave function $u$. Thus, $E[\min \{x+\tilde{Y},(1+r)(1-w)\}] \geq E[\min \{x+Y,(1+$ $r)(1-w)\}]$. This, and (4) implies

$$
E\left[\min \left\{x_{D}+\tilde{Y},(1+r)(1-w)\right\}\right] \geq\left(1+r_{i}\right)(1-w)
$$

From Proposition 3 we can conclude that constraint (5) must hold with equality when the noise is $Y$. Let $\tilde{x}_{D}$, and $\tilde{r}$ be the cutoff value for providing finance and the interest rate, respectively, when the noise is $\tilde{Y}$.

First, suppose that $\tilde{x}_{D}<x_{D}$ and $\tilde{r}>r$. Then it follows immediately constraint (5) holds with a strict inequality. However, $\tilde{x}_{D}<x_{D}$ implies that there is also over-financing under $\tilde{Y}$. Because of Proposition 3 , constraint (5) must therefore hold with equality, a contradiction.

Next, suppose that $\tilde{x}_{D}>x_{D}$ and $\tilde{r}<r$. Then the left-hand side of constraint (5) strictly increases. Hence, constraint (5) is violated, again a contradiction. Inequality (13) therefore implies that $\tilde{x}_{D}<x_{D}$ and $\tilde{r}<r$.

Finally, note that $\tilde{x}_{D}<x_{D}$ implies that the surplus decrease because over-financing is increased. Because the financier's payoff does not change, the entrepreneur's payoff must therefore decrease.

Proof of Proposition 5. We first provide the proof for changes of $r_{i}$. If there is over-financing, then Proposition 3 implies that constraint (5) binds. The optimal values $x_{D}\left(r_{i}\right)$, and $r\left(r_{i}\right)$ are therefore given by equation (4) and constraint (5), i.e.,

$$
\int_{x_{D}\left(r_{i}\right)}^{\infty}\left[\int_{-\infty}^{\left(1+r\left(r_{i}\right)\right)(1-w)-x}(x+y) d G(y)+\int_{\left(1+r\left(r_{i}\right)\right)(1-w)-x}^{\infty}\left(1+r\left(r_{i}\right)\right)(1-w) d G(y)\right] d F(x)=c+\bar{u}
$$


and

$$
\int_{-\infty}^{\left(1+r\left(r_{i}\right)\right)(1-w)-x_{D}(r)}\left(x_{D}(r)+y\right) d G(y)+\int_{\left(1+r\left(r_{i}\right)\right)(1-w)-x_{D}\left(r_{i}\right)}^{\infty}\left(1+r\left(r_{i}\right)\right)(1-w) d G(y)=\left(1+r_{i}\right)(1-w) .
$$

Differentiating (14) with respect to $r_{i}$ and using (15) yields

$$
\int_{x_{D}\left(r_{i}\right)}^{\infty}\left[r^{\prime}\left(r_{i}\right)(1-w)(1-G((1+r)(1-w)-x))-(1-w)\right] d F(x)=0,
$$

which implies

$$
r^{\prime}\left(r_{i}\right)=\frac{1-F\left(x_{D}\left(r_{i}\right)\right)}{\int_{x_{D}\left(r_{i}\right)}^{\infty}[1-G((1+r)(1-w)-x)] d F(x)} .
$$

We can assume that $G\left((1+r)(1-w)-x_{D}\right)>0$. Otherwise, if $G\left((1+r)(1-w)-x_{D}\right)=0$ then (15) implies $x_{D}=\left(1+r_{i}\right)(1-w)$ and the result follows, i.e., $x_{D}$ increases when $r$ increases. Thus, $G((1+r)(1-w)-x)<G\left((1+r)(1-w)-x_{D}\right)$, for some $x>x_{D}$. This, and (16) imply

$$
r^{\prime}\left(r_{i}\right)<\frac{1-F\left(x_{D}\left(r_{i}\right)\right)}{\int_{x_{D}\left(r_{i}\right)}^{\infty}\left[1-G\left((1+r)(1-w)-x_{D}\left(r_{i}\right)\right)\right] d F(x)}=\frac{1}{1-G\left((1+r)\left(1-w-x_{D}\left(r_{i}\right)\right)\right)} .
$$

Differentiating (15) with respect to $r_{i}$ yields

$$
\int_{-\infty}^{(1+r)(1-w)-x_{D}(r)} x_{D}^{\prime}\left(r_{i}\right) d G(y)=(1-w)\left[1-\left(1-G\left((1+r)\left(1-w-x_{D}(r)\right)\right) r^{\prime}\left(r_{i}\right)\right)\right]>0,
$$

where the inequality follows from (17). Hence, $x_{D}^{\prime}\left(r_{i}\right)>0$.

We sketch the proof for $w$, as the key steps are qualitatively identical. Differentiating (14) with respect to $w$ and using (15) yields

$$
r^{\prime}(w)=\frac{1+r}{1-w}-\frac{\left(1+r_{i}\right)\left(1-F\left(x_{D}\right)\right)}{\int_{x_{D}(w)}^{\infty}[1-G((1+r)(1-w)-x)] d F(x)}
$$

which again implies

$$
r^{\prime}(w)>\frac{1+r}{1-w}-\frac{\left(1+r_{i}\right)\left(1-F\left(x_{D}(w)\right)\right)}{1-G\left((1+r)(1-w)-x_{D}(w)\right)} .
$$

Differentiating (15) with respect to $w$ yields

$$
\int_{-\infty}^{(1+r)(1-w)-x_{D}(w)} x_{D}^{\prime}(w) d G(y)=\left[(1+r)-r^{\prime}(w)(1-w)\right]\left[1-G\left((1+r)\left(1-w-x_{D}(w)\right)\right)-\left(1+r_{i}\right)\right]
$$

Substituting (19) for $r^{\prime}(w)$ in (20) reveals that $x_{D}^{\prime}(w)<0$.

Increasing $c$ or $\bar{u}$ raises $r$. The result then follows immediately. 


\section{References}

[1] P. Aghion and P. Bolton. An incomplete contracts approach to financial contracting. Review of Economic Studies, 59:473-494, 1992.

[2] S. Ambec and M. Poitevin. Organizational design of r\&d activities. working paper: University of Montreal, 2001.

[3] D. Bergemann and U. Hege. Dynamic venture capital financing, learning and moral hazard. Journal of Banking and Finance, 22:703-735, 1998.

[4] D. Bernhardt and S. Krasa. Informed finance? working paper: University of Illinois, 2004.

[5] B. Biais and E. Perotti. Entrepreneurs and new ideas. working paper: CEPR, 2002.

[6] B. Byers. Relationship between venture capitalist and entrepreneur. In Pratt's Guide to Venture Capital Sources. Wellesley Hills, MA, 1997.

[7] W. Bygrave and J. Timmons. Venture Capital at the Crossroads. Harvard University Press, Boston, MA, 1992.

[8] P. Chen, G. Baierl, and P. Kaplan. Venture capital and its role in strategic asset allocation. Journal of Portfolio Management, 28:83-90, 2001.

[9] J. H. Cochrane. The risk and return of venture capital. working paper: GSB Chicago, 2003.

[10] M. Dewatripont and J. Tirole. A theory of debt and equity: Diversity of securities and manager-shareholder congruence. Quarterly Journal of Economics, 109:1027-1054, 1994.

[11] G. Fenn, G. N. Liang, and S. Prowse. The economics of private equity markets. Staff Study 168, Board of Governors of the Federal Reserve System, 1995.

[12] V. H. Fried and R. D. Hisrich. Toward a model of venture capital investment decision making. Financial Management, 23:28-37, 1994.

[13] M. Garmaise. Informed investors and the financing of entrepreneurial projects. working paper: GSB Chicago, 2001.

[14] M. Gorman and W. Sahlman. What do venture capitalists do. Journal of Business Venturing, 4:231-248, 1989.

[15] O. Hart and J. Moore. Default and renegotiation: A dynamic model of debt. Quarterly Journal of Economics, 3:1-41, 1998.

[16] T. Hellmann and M. Puri. The interaction between product market and financing strategy: the role of venture capital. Review of Financial Studies, 13:959-984, 2000.

[17] S. Kaplan and P. Stromberg. How do venture capitalists choose and manage their investments? working paper: University of Chicago, 2000.

[18] S. Kaplan and P. Stromberg. Financial contracting theory meets the real world: An empirical analysis of venture capital contract. Review of Economic Studies, 70:281-315, 2003.

[19] A. Ljungqvist and M. Richardson. The cash flow, return and risk characteristics of private equity. working paper: NYU, 2003.

[20] R. Mehra and E. C. Prescott. The equity premium: A puzzle. Journal of Monetary Economics, 15:145-161, 1996.

[21] R. Meyer, R. Radosevich, E. Carayannis, M. David, and J. G. Butler. The 1995 national census of early-stage capital financing. http://www.oriontechnical.com/95report.html, 1995.

[22] R. Repullo and J. Suarez. Venture capital finance: A security design approach. working paper, CEMFI, 1999.

[23] H. Sapienza. When do venture capitalists add value? Journal of Business Venturing, 7:9-27, 1992.

[24] M. Ueda. Banks versus venture capital: Project evaluation, screening, and expropriation. Journal of Finance, 59:601-621, 2004.

[25] A. Winton and V. Yerramilli. A model of entrepreneurial finance. working paper: University of Minnesota, 2004. 